\title{
Exercise after Heart Transplantation: Typical Alterations, Diagnostics and Interventions
}

\author{
Authors \\ Thomas Schmidt ${ }^{1,2}$, Birna Bjarnason-Wehrens ${ }^{2}$, Hans-Georg Predel², Nils Reiss ${ }^{1}$
}

Affiliations

1 Institute for Cardiovascular Research, SchüchtermannKlinik Bad Rothenfelde, Bad Rothenfelde, Germany

2 Department of Preventive and Rehabilitative Sport and Exercise Medicine, Institute for Cardiology and Sports Medicine, Cologne, German Sport University Cologne, Germany

\section{Key words}

heart failure, heart transplantation, transplant-related alterations, exercise testing, exercise training, exercise capacity

accepted 24.05.2020

published online 20.07 .2020

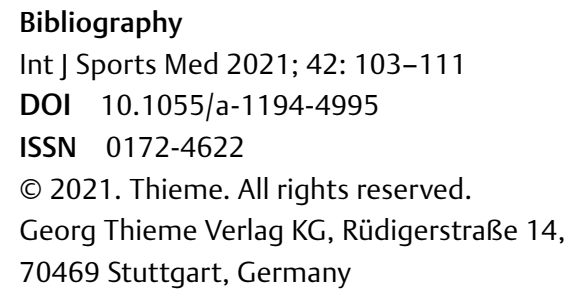

\section{Correspondence}

Dr. Thomas Schmidt

Institute for Cardiovascular Research, Schüchtermann-Klinik Bad Rothenfelde, Ulmenallee 5-11

49214 Bad Rothenfelde

Germany

Tel.: 0049542464130046 , Fax : 00495424641270

tschmidt@schuechtermann-klinik.de

\begin{abstract}
For the treatment of terminal heart failure, heart transplantation is considered to be the gold standard, leading to significantly improved quality of life and long-time survival. For heart transplant recipients, the development and maintenance of good functional performance and adequate exercise capacity is crucial for renewed participation and integration in self-determined live. In this respect, typical transplant-related alterations must be noted that play a significant role, leading to restrictions both centrally and peripherally. Before patients begin intensive and structured exercise training, a comprehensive diagnosis of their exercise capacity should take place in order to stratify the risks involved and to plan the training units accordingly. Particularly endurance sports and resistance exercises are recommended to counter the effects of the underlying disease and the immunosuppressive medication. The performance level achieved can vary considerably depending on their individual condition, from gentle activity through a non-competitive-level to intensive competitive sports. This paper includes an overview of the current literature on heart transplant recipients, their specific characteristics, as well as typical cardiovascular and musculoskeletal alterations. It also discusses suitable tools for measuring exercise capacity, recommendations for exercise training, required precautions and the performance level usually achieved.
\end{abstract}

\section{Introduction}

Heart failure (HF) has a prevalence of $1-2 \%$, making it one of the most widespread adult diseases in Europe. Between 6 and $25 \%$ of HF patients are currently in the advanced stages of this disease. This tendency is on the increase, with the incidence of HF rising as patients live longer due to improved and innovative treatment options [1-3].

The gold standard for treating terminal HF is still heart transplantation (HTX), even in this age of donor shortages [4]. Compared with conventional treatment or treatment using a left ventricular assist device (LVAD), HTX improves survival rates, exercise tolerance and quality of life [5]. The survival rates after one, five, and ten years are currently approx. 85,75 , and $60 \%$, respectively $[6,7]$. With these survival times, the optimum build-up of exercise capacity and functional performance is therefore crucial.
With reference to the latest literature, this overview describes common patient characteristics, typical transplant-related alterations to the musculoskeletal and cardiovascular system, as well as general requirements and precautions with regard to sports activities after HTX. It also discusses suitable tools for measuring exercise capacity, recommendations for exercise training and the performance level usually achieved after transplantation.

\section{Patient characteristics}

Currently, about 5000 HTXs per year are performed worldwide, with a slightly increasing overall tendency. Median survival after HTX in adults is now 12.5 years and extends to 15 years to 1 -year survivors [7]. About $75 \%$ of all recipients are male with a mean age at transplantation of 55 years. However, the age range for recipi- 
ents is quite large, with $30 \%$ of patients younger than 40 years and $30 \%$ of patients older than 60 years, leading to different physical overall prerequisites [7].

The main indications for HTX in adults are usually non-ischaemic dilated cardiomyopathy (51\%) (e. g. due to doxorubicin, alcoholism, familial condition, myocarditis, post-partum cardiomyopathy) or ischaemic cardiomyopathy (32\%) [6-9]. About half of all patients are bridged with mechanical circulatory support (MCS) prior to transplantation, mainly by the use of LVADs [7]. In these patients, LVAD-related complications are often the reason for highurgency listing and transplantation (mostly anticoagulation complications, driveline infections or device failure) [10].

Prior to HTX, many patients already suffer from concomitant diseases, such as hypertension (51\%), diabetes mellitus (27\%) or hyperlipidaemia, which also remain after surgery. In addition, the following transplant-related complications can occur and influence prognosis and clinical condition significantly: early graft failure, rejection, cardiac allograft vasculopathy (CAV), late graft failure, severe renal dysfunction, malignancy (mostly skin cancers), or infections [7-9].

Participation in a cardiac rehabilitation programme after discharge from acute hospital care varies amongst the different countries and also depends on the patient's degree of debility [11]. The overall readmission rate after $\mathrm{HTX}$ is highest in the first year $(40 \%$ of patients) and decreases clearly in the long term (25\% are readmitted in the time between 2 and 5 years) [7]. Specific outpatient checkups at the individual transplant centre are initially performed frequently and can later be reduced to once a year.

With regard to exercise, the following musculoskeletal and cardiovascular alterations must also be considered after HTX ( $\vee$ Fig. 1):

\section{Alterations to the musculoskeletal system}

Clinical condition following HTX is determined not only by the individual anamnesis, by the altered haemodynamics of the transplanted heart, and the sequelae of life-long immunosuppression, but also and especially by damage incurred prior to HTX [12]. The period before HTX is usually characterised by long phases of disease, so that patients usually display significant deconditioning of the peripheral muscles due to inactivity [13-15]. Muscle fibre composition changes from type I to types Ila and IIb. Following HTX, the muscle cross-sectional area does usually grow in size again, but the proportion of type I muscle fibres remains reduced, even in the long term [16-18].

A prolonged obstacle to effective muscle training is the required immunosuppressive therapy (calcineurin inhibitors, corticosteroids). This is partly due to the resulting chemical impairment of muscular structures (mitochondria) but also to the changed supply of energetic substances within the muscles, leading to impaired oxidative function [19]. Consequently, an HTX patient has to complete significantly more training units than a non-immunosuppressed person in order to achieve the same increase in muscle mass. Because this is not possible during the early stages owing to very restricted exercise tolerance, transplant recipients require considerable time to make up their deficits. In addition, the intake of corticosteroids in conjunction with physical inactivity leads to a decrease in bone density [20] and possible osteoporotic fractures [15]. a Main influencing factors:

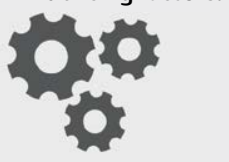

- History of heart failure and inactivity

- Denervation of cardiac nerve fibres

- Need for immunosuppressive medications

- Transplant-related complications

b Musculoskeletal system

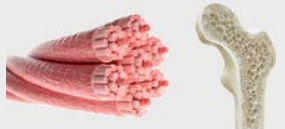

- Shift from type I to type II muscle fibres

- Impaired mitochondrial function

- Decrease in bone density

c Cardiovascular system

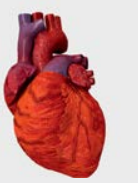

- High resting heart rate

- Chronotropic incompetence

- Impaired diastolic function

- Reduced maximum cardiac output

- Fig. 1 Typical alterations after heart transplantation: main influencing factors (a) that lead to changed prerequisites for both the musculoskeletal (b) and cardiovascular system (c). Regular structured exercise can counteract most of these changes and improve functional performance significantly.

\section{Alterations to the cardiovascular system}

Following HTX, the cardiovascular system changes significantly [12]. Transplantation leads to a denervation of the sympathetic and parasympathetic nerve fibres. This denervation is responsible for numerous physiological phenomena usually observed in HTX patients, e. g. a high resting heart rate (HR) (approx. 95 bpm), a delayed increase in HR during exercise (chronotropic incompetence), delayed achievement of resting HR during the recovery phase following exercise, and significantly restricted HR variability [21-23].

Denervation gradually leads to an emptying of the catecholamine storage in the myocardium, meaning that the transplanted heart is then reliant on the stimulation of circulating catecholamines [21,23]. Overall, the catecholamine receptors display an increased sensitivity. In an unfavourable case, this can lead to an increased incidence of arrhythmia, whereby therapy with beta blockers is not a viable option because it significantly reduces exercise tolerance.

In conjunction with chronotropic incompetence, the donor heart must increase its stroke volume (SV) during physical exercise via the Frank-Starling mechanism so that cardiac output (CO) can be adapted at least partially to the degree of exertion. In many patients, however (especially during the initial phase), insufficient relaxation/compliance of the left ventricle can be observed (diastolic dysfunction) [24, 25]. The consequence is an increased end-diastolic pressure in the left ventricle despite reduced end-diastolic volume. This in turn impinges the Frank-Starling mechanism, accompanied by non-optimal adaptation of SV during physical activity [26]. Overall, CO remains reduced both at rest and during exercise, and often only a low rise in systolic blood pressure can be generated [27-29].

Partial reinnervation is fundamentally possible after HTX and has a clinical impact on exercise capacity. In total, $40-70 \%$ of patients display cardiac reinnervation over the long term. Corre- 
sponding changes can be observed very early (approx. 6 months) in the sympathetic nerve fibres, and later (after $1-3$ years) in the parasympathetic nerve fibres [22]. Despite long-term compensation mechanisms, however, the result still remains reduced in comparison to persons with healthy hearts [22].

In addition to these cardiac changes, persisting lung damage can also be observed in the pulmonary capillary beds of many patients due to their long-term HF.

\section{Efficacy and benefits of exercise-based interventions}

In stable HTX patients exercised-based interventions are recommended [12, 30-32]. Results from a smaller retrospective study provide first indications of a protective effect of exercise-based rehabilitation immediately after HTX [33]. They show a significant association between the number of completed rehabilitation units in the first 90 days after HTX and survival rates (hazard ratio, 0.90, $95 \% \mathrm{Cl}, 0.82-0.97, \mathrm{p}=0.007$ ) [33]. In the meantime, the efficacy of exercise-based rehabilitation on peak oxygen consumption (peak $\mathrm{VO}_{2}$ ) has been confirmed (MD $2.49 \mathrm{ml} / \mathrm{kg} / \mathrm{min}, 95 \% \mathrm{Cl}, 1.63-3.36$ ) by a meta-analysis of 9 studies including 284 patients [34]. Only one of the studies evaluated documented adverse events.

The ability of moderate intensity continuous training (MICT) (e. g. at 60-70\% peak $\mathrm{VO}_{2}$ ) to improve exercise capacity in HTX patients has been confirmed by meta-analyses and systematic reviews including a few smaller studies [35-37]. Other documented positive effects of MICT are increase in peak HR, improvement in the oxidative capacity of skeletal muscle [38], improvement in blood pressure [39], improvement in endothelial function [40-42], and improvement in quality of life [43-46].

Randomised controlled trials have also confirmed the feasibility and efficacy of high intensity interval training (HIIT) in HTX patients. These studies show that interval training can be considered in longterm care ( $>1$ year after HTX) but also earlier (11 weeks after HTX [47]), with positive improvements in peak $\mathrm{VO}_{2}$ [47-51], muscular exercise capacity [47, 48], endothelial function [52], and quality of life [53], with reduced anxiety and depression [53].

The results of a randomised crossover study show low superiority of HIIT vs. MICT ( $>80 \%$ peak $\mathrm{VO}_{2}$ vs. $60-70 \%$ peak $\mathrm{VO}_{2}$ ) in terms of improvement in exercise capacity and quality of life [54, 55]. Regarding compliance aspects (attendance or dropouts), another randomised controlled study [47] revealed no differences between HIIT and MICT (each 58/72 or $82 \%$ of sessions were performed), indicating that both exercise modalities are well tolerated and accepted. However, experiences with HIIT in other cardiovascular patient populations [56-58] showed that a larger proportion of patients were unable to maintain high intensities over longer periods (e. g. 4-min intervals).

Moderate resistance training (50-60\% of 1 repetition maximum [1RM]) improves muscle strength [36] and counteracts the negative effects of immunosuppressive therapy on muscle and bone metabolism [15, 59-61]. Studies have also demonstrated that resistance training programmes successfully restore bone mineral density and increase lean mass to levels greater than pre-transplantation, as well as reduce body fat [19].

In addition to the positive physical effects described, structured exercise training can also achieve significant mental benefits. Particularly during the initial phase after HTX, many patients suffer from bouts of depression [62]. Increasing exercise capacity and/or training within a social group has the potential to significantly improve the moods and quality of life of these patients. Assuming that they meet the necessary physical criteria, participation in sports competitions (e. g. The World Transplant Games) can also be beneficial, accompanied by a reinforcement of self-confidence and expected self-efficacy.

However, the general impact of exercise on the progression of CAV (regardless of specific training modalities) needs further investigation $[35,63]$.

\section{Assessment of functional and cardiopulmonary exercise capacity}

Before the onset of exercise training, adequate diagnostics should be performed [12]. With the help of a substantiated assessment of functional and cardiopulmonary exercise capacity, the cardiopulmonary, metabolic, and muscular exercise tolerance of HF patients can be objectively determined [64]. In HTX patients, these results can facilitate evaluation of patient condition and individual risk stratification, as well as provide indications about the long-term prognosis [66-69]. A substantiated assessment is a prerequisite for planning the content of effective exercise training units, for individual exercise control, and also for monitoring recovery. These diagnostic measures are especially crucial for patients who would like to pursue sports activities unsupervised.

- Table 1 provides a summary of potential assessment procedures for testing functional and cardiopulmonary exercise capacity in HTX patients, whereby modifications are necessary to suit the current health status of the individual patient [64, 65, 70-79]. In addition, performance-limiting comorbidities, especially internal, neurological or orthopaedic, should be collected, documented and considered.

Besides objective parameters, the rated perception of exertion (RPE) of patients should definitely also be recorded in order to train adequate self-perception and to prepare for the challenges of everyday life. In addition to the assessment procedures suggested in - Table 1, specific sports diagnostics are also possible and recommended in patients with sporting ambitions.

\section{Precautions before and during physical exercise training}

Before starting intensive exercise training, as well as at regular intervals thereafter, an ischaemia diagnosis is recommended due to the possibility of CAV and related sudden cardiac death because a denervated heart gives no warning symptoms (silent ischaemia) [80]. The results from a cardiopulmonary exercise test (CPET) are of no use here owing to its insufficient sensitivity [81]. Therefore, CAV diagnostics will be performed usually annually during the outpatient checkups at the transplant centre. Depending on renal function and previous findings, either dobutamine stress echocardiography (DSE) and/or invasive coronary angiography are commonly used. If the results are unclear, further investigations (e. g. intravascular ultrasound (IVUS) or coronary flow reserve (CFR)) are needed to obtain safe sport release [82,83].

In general, planning and execution of exercise training after HTX must always be adapted to the current clinical condition, the individual comorbidities and possible transplant-related complications. 
- Table 1 Possible assessments for testing of functional and cardiopulmonary exercise capacity in heart transplant recipients [64, 65, 70-79].

\begin{tabular}{|c|c|c|c|}
\hline & Test & Test protocol & Measurement parameters \\
\hline \multirow[t]{2}{*}{$\begin{array}{l}\text { Functional } \\
\text { assessment }\end{array}$} & 6-min walking test & ATS standard with/without aids & $\begin{array}{l}\text { Distance, RPE, usage of aids, number/duration of recovery } \\
\text { periods, reason for stopping }\end{array}$ \\
\hline & $\begin{array}{l}\text { Timed up and go } \\
\text { test* }\end{array}$ & Standard with/without aids & $\begin{array}{l}\text { Time, usage of aids, certainty of movement, mobility } \\
\text { classification }\end{array}$ \\
\hline \multirow[t]{3}{*}{ Ergometry } & CPET on bicycle & $\begin{array}{l}\text { 1. Ramp (5-15 watts/min) } \\
\text { 2. WHO Step ( } 25 \text { watts } / 2 \text { min) } \\
\text { 3. In patients with good exercise tolerance, higher } \\
\text { increases/steps are also conceivable }\end{array}$ & $\begin{array}{l}E C G, H R \text {, watts, RPE, exercise duration, reason for stopping, } \\
\mathrm{VO}_{2}, \mathrm{VE} / \mathrm{VCO}_{2} \text { slope, RER, lactate, oxygen saturation, values } \\
\text { at VAT, periodic breathing }\end{array}$ \\
\hline & $\begin{array}{l}\text { CPET on tread- } \\
\text { mill ** }\end{array}$ & $\begin{array}{l}\text { 1. Select protocol with constant low speed and } \\
\text { increase load by increasing elevation } \\
\text { 2. In patients with good exercise tolerance, } \\
\text { increasing speed is also conceivable }\end{array}$ & $\begin{array}{l}\text { ECG, } \mathrm{HR} \text {, elevation, speed, RPE, exercise duration, reason } \\
\text { for stopping, } \mathrm{VO}_{2}, \mathrm{VE} / \mathrm{VCO}_{2} \text { slope, RER, lactate, oxygen } \\
\text { saturation, values at VAT, periodic breathing }\end{array}$ \\
\hline & IGR on bicycle & 4-min step protocol at different exercise levels & $\begin{array}{l}\mathrm{ECG}, \mathrm{HR} \text {, watts, } \mathrm{RPE}, \mathrm{VO}_{2}, \mathrm{CO} \text {, avDO } \\
\text { saturation, systolic blood pressure, cardiac index }\end{array}$ \\
\hline \multirow[t]{2}{*}{$\begin{array}{l}\text { Strength } \\
\text { assessment }\end{array}$} & $\begin{array}{l}\text { Handgrip strength } \\
\text { test }\end{array}$ & Standard one-arm for both right and left hand & Newtons, kg, lbs \\
\hline & $\begin{array}{l}\text { Strength training } \\
\text { with machines or } \\
\text { barbells }\end{array}$ & $\begin{array}{l}\text { 1. Submaximal test to predict } 1 \mathrm{RM} \\
\text { 2. In patients with high strength training experience, } \\
1 \mathrm{RM} \text { test is also conceivable }\end{array}$ & Newton, kg, lbs, repetitions \\
\hline \multicolumn{4}{|c|}{$\begin{array}{l}\text { Abbreviations: }{ }^{*} \text {, only in patients with } 6 \text {-min walking distance below } 200 \mathrm{~m} \text { and using aids; }{ }^{*}{ }^{*} \text {, only for patients without balance disorders; } 1 \mathrm{RM}, \text { one } \\
\text { repetition maximum; ATS, American Thoracic Society; } \mathrm{avDO}_{2} \text {, arteriovenous oxygen difference; } \mathrm{CO} \text {, cardiac output; } \mathrm{CPET} \text {, cardiopulmonary exercise test; } \\
\mathrm{CR} \text {, cardiac rehabilitation; ECG; electrocardiogram; } \mathrm{HR} \text {, heart rate; IGR, inert gas rebreathing; } \mathrm{RER} \text {, respiratory exchange ratio; } \mathrm{RPE} \text {, rated perceived } \\
\text { exertion; VAT, ventilator anaerobic threshold; } \mathrm{VE} / \mathrm{VCO}_{2} \text { slope, relation between ventilation and carbon dioxide production; } \mathrm{VO}_{2} \text {, oxygen uptake; WHO, } \\
\text { World Health Organization. }\end{array}$} \\
\hline
\end{tabular}

A potential negative influence of the individual medication regime on exercise therapy must also be considered. Thus, statins are usually prescribed to prevent the progression of CAV, but their use is often accompanied by side effects such as muscle pain, tensions, stiffness, cramps, or muscle weakness [84].

Indications of possible rejection episodes should be heeded (e. $\mathrm{g}$. low stress tolerance, shortness of breath, oedemas, cardiac dysrhythmia, raised or high temperature). In order to recognise these episodes early on, it makes sense to measure and document body temperature, blood pressure, fluid balance, and weight every day, at least in the first few weeks or months. During rejection episodes, the intensity of exercise training must be clearly reduced. In case of cortisone bolus therapy, it must be stopped completely [31]

A must for all patients: fluid balance must be regulated due to the volume dependence of cardiac performance after cardiac denervation. Due to the delayed circulatory reactions, warm-ups prior to exercise training should be fundamentally slower and longer than for e. g. other coronary groups. Exercise training should not be started or stopped abruptly.

Attention should also be paid during exercise training to appropriate environmental conditions with low risks of injury or germ contamination (e.g. patients should avoid exposure to bird droppings due to possible risk of cryptococcosis infection) [85]. Fortunately, patients are usually well educated regarding these important issues.

\section{Recommendations for endurance training}

After HTX, haemodynamically stable patients should participate in medically supervised exercise-based measures, and all training measures should be continued in the long term [12, 30-32, 86].
Patients should be introduced as early as possible $\left(2^{\text {nd }}\right.$ to $3^{\text {rd }}$ week postoperatively) to monitored endurance training [30-32]. The International Society for Heart and Lung Transplantation (ISHLT) therefore suggests the routine use of a cardiac rehabilitation programme after HTX with a class Ib recommendation. Regular endurance training is especially valuable in heart transplant recipients with internal comorbidities (e. g. hypertension or diabetes mellitus) [30].

In general, different exercise modalities are established and recommended, including MICT, intensive interval training with short intervals or HIIT. Their individual use depends on the clinical status and later on the patient's preferences.

Shortly after transplantation, endurance training should be started with MICT at low intensity ( $<50 \%$ of the peak $\mathrm{VO}_{2}$ or $10 \%$ below the first ventilatory threshold) [32]. Exercise intensity should be determined using the Borg scale (RPE 11-14) and/or the respiratory rate ("speech rule"), which means that the respiratory rate should permit conversation [31, 32]. Intensity of MICT can also be defined as up to $50 \%$ of the maximum load (watt) achieved during CPET [31, 32]. In very weak patients, intensive interval training with short intervals (20-30 s) could also be an option to induce first exercise tolerance.

In the further course, clinically stable patients with good exercise tolerance can gradually be brought up to more intensive endurance training (e. g. MICT at $60-80 \%$ of peak $\mathrm{VO}_{2}$ ), possibly also in the form of HIIT, if tolerated [35, 47]. In addition, combined methods are also thinkable (e.g. 1 day HIIT and 3 days MICT), whereby MICT is suggested as the basic exercise mode. The summarized exercise recommendations and selected control parameters are shown in $>$ Table $2,[12,58,86]$. 
With regard to exercise control, the use of HR to determine exercise intensity after HTX is problematic due to chronotropic incompetence. For experienced athletes, however, HR can at least be viewed as complementary to the Borg scale. HR ranges must then be determined individually, depending on the HR pattern, and only make sense for MICT (not intensive interval training with short intervals or HIIT).

\section{Recommendations for resistance training}

Moderate and individually dosed resistance training (30-60\% of 1 RM) should be integrated into the exercise regime postoperatively as soon as possible [12, 30-32, 86]. In particular, resistance training is suitable for counteracting the catabolic side-effects of immunosuppressive therapy and the loss of muscle mass, muscle strength and bone density caused preoperatively by $\mathrm{HF}$ and inactivity [19]. Therefore, the guidelines of the ISHLT suggest regular resistance training with class $1 \mathrm{~b}$ recommendation, especially to re- duce the risk of falls and fractures [30]. Muscles of the lower extremities should be given priority because they are important for activities of daily living (e.g. walking, climbing stairs) and are an essential prerequisite for improved participation. In general, all measures performed shortly after HTX should be gentle on the patient's sternum due to surgery. A gradual increase in upper-extremity extent of motion and resistance training should be considered up to 3 months after transplantation [11].

In the further course, the intensity can be gradually increased (up to $60-80 \%$ of $1 \mathrm{RM}$ ) in experienced patients with good exercise tolerance ( $\triangleright$ Table 2 ).

\section{Exercise capacity and sports activities}

Despite the described pathomorphological changes to the heart and motor apparatus, functional performance increases significantly after HTX. The mean six-minute walking distance (6MWD) achieved is usually 500 metres or more ( $>85 \%$ of predicted), and the ability

- Table 2 Recommended exercise modalities for patients after heart transplantation: (a) Moderate intensity continuous training (MICT) is suggested as basic exercise mode. (c) High intensity interval training (HIIT) should be introduced only in the further course of clinically stable patients $[12,58,86]$.

\begin{tabular}{|c|c|c|}
\hline \multicolumn{3}{|c|}{ a) Moderate intensity continuous training (MICT) } \\
\hline & Low to moderate intensity & Moderate to high intensity \\
\hline$\%$ of peak $\mathrm{VO}_{2}(\mathrm{ml} / \mathrm{kg} / \mathrm{min})$ & $40-60 \%$ & $60-80 \%$ \\
\hline$\%$ of peak load (watts) & $40-60 \%$ & $60-80 \%$ \\
\hline Borg Scale & RPE $11-14$ & $\mathrm{RPE} \geq 15$ \\
\hline Respiratory rate & \multicolumn{2}{|c|}{ Respiratory rate should permit conversation (speech rule) } \\
\hline Duration & \multicolumn{2}{|l|}{ From 5 up to $\geq 60 \mathrm{~min}$} \\
\hline Frequency & \multicolumn{2}{|c|}{ 3-5 (7) days per week/most days of the week } \\
\hline \multicolumn{3}{|c|}{ b) Intensive interval training with short intervals } \\
\hline & High intensity phase & Recovery phase \\
\hline$\%$ of peak $\mathrm{VO}_{2}(\mathrm{ml} / \mathrm{kg} / \mathrm{min})$ & $\geq 80 \%$ & very low \\
\hline$\%$ of peak load (watts) & $\geq 80 \%$ & very low \\
\hline Borg Scale & RPE $>15$ & $\mathrm{RPE} \leq 11$ \\
\hline Duration & \multicolumn{2}{|c|}{$20-30$ s high intensity vs. $40-60$ s recovery; 10 to $\geq 20$ intervals } \\
\hline Frequency & \multicolumn{2}{|c|}{ 3-5 (7) days per week/most days of the week } \\
\hline \multicolumn{3}{|c|}{ c) High intensity interval training (HIIT) } \\
\hline & High intensity phase & Recovery phase \\
\hline$\%$ of peak $\mathrm{VO}_{2}(\mathrm{ml} / \mathrm{kg} / \mathrm{min})$ & $\geq 80 \%$ & $40-60 \%$ \\
\hline$\%$ of peak load (watts) & $\geq 80 \%$ & $40-60 \%$ \\
\hline Borg Scale & RPE $>15$ & RPE 11-13 \\
\hline Duration & \multicolumn{2}{|c|}{$\leq 4 \mathrm{~min}$ high intensity vs. $3 \mathrm{~min}$ recovery; $\leq 4$ intervals } \\
\hline Frequency & \multicolumn{2}{|c|}{2 days per week with at least 1 resting day in between } \\
\hline \multicolumn{3}{|l|}{ d) Resistance training } \\
\hline & Low to moderate intensity & Moderate to high intensity \\
\hline$\%$ of 1 RM & $30-60 \%$ & $60-80 \%$ \\
\hline Repetitions & $10-15$ & $8-10$ \\
\hline Borg Scale & RPE $11-14$ & $\mathrm{RPE} \geq 15$ \\
\hline Sets & $1-(3)$ & $1-3$ \\
\hline Resting time between sets & \multicolumn{2}{|l|}{$>1 \mathrm{~min}$} \\
\hline Progression & \multicolumn{2}{|l|}{ Gradual increase } \\
\hline Number of exercises & \multicolumn{2}{|l|}{$4-8$} \\
\hline Frequency & \multicolumn{2}{|c|}{ 2-3 days per week - with resting day in between } \\
\hline
\end{tabular}


to master everyday tasks is very good $[70,87,88]$. With regard to their symptoms, $90 \%$ of patients return to New York Heart Association (NYHA) class I or II after HTX, i. e. no longer or just slightly restricted [89].

However, the recorded peak values remain below those of an age-matched group with healthy hearts [90]. In the CPET, a peak $\mathrm{VO}_{2}$ of approx. $16-20 \mathrm{ml} / \mathrm{kg} / \mathrm{min}$ is usually measured, corresponding to around $60-70 \%$ of predicted values [35]. Of course this is considerably better than in the phase directly before HTX [90] and also better than results after LVAD implantation [91, 92], but it still remains reduced compared to healthy patients. Significantly better values can be achieved only in individual patients, sometimes even at the level of high-performance sports activity [93]. These are usually patients who participated intensively in top-level sport prior to their heart transplant and who also exercised regularly and intensively after HTX. In our experience, these patients do not generate an exaggerated maximum CO after transplantation (as one would assume) but profit considerably from optimal peripheral structures and processes (improved oxygen extraction during peak exercise, optimised inter- and intramuscular coordination). To provoke such adaptations, regular exercise interventions are needed.

Many different sports activities are thus not only possible after HTX but also recommended. Endurance sports, such as running, jogging, walking, cycling, hiking, cross-country skiing, gymnastics, and yoga, are suitable. Swimming and aquafit are also options, provided that certain hygienic criteria (e. g. a microbiologically controlled swimming pool) are met. In contrast, all sports activities with an increased risk of injury and/or infection (e. g. contact sports, swimming in microbiologically contaminated water) are not recommended.

With regard to organised sport, there are some options for structured exercise training and competitions already available. Patients with other transplanted organs (e. g. kidney or liver) or patients requiring dialysis treatment are often also included in such clubs and events. The current exercise possibilities for transplant recipients include: related sports clubs, national championships, European championships and also world championships. Mostly summer sports are offered, but winter games also sometimes take place. The current leading international associations include the European Heart and Lung Transplant Federation (EHLTF), the European Transplant and Dialysis Sports Federation (ETDSF), and the World Transplant Games Federation (WTGF).

However, there are also HTX patients who participate in "normal" sport programmes and competitions (for healthy hearts) or sporting challenges, in individual cases with impressive results, such as finishing the Hawaii Ironman or the summit ascent of high mountains [93]. Thus, the performance level after HTX can vary considerably depending on the individual (age, concomitant diseases, previous experience, training frequency, and grade of reinnervation), from low intensity (e. g. heart groups) to a non-competitive level, and up to intensive competitive sports.

\section{Conclusion and Outlook}

HTX improves quality of life considerably, with a crucial role being played by the increase in exercise capacity. After transplantation, patients usually achieve a peak $\mathrm{VO}_{2}$ which is approx. $60-70 \%$ of predicted values. This is considerably better than in the phase directly before HTX [90] and also better than results after LVAD implantation [91]. But in comparison to age-matched healthy test persons, the values are still reduced. However, the reached exercise capacity permits patients to master everyday tasks very well as well as to participate in many different sports activities. In exceptional cases, with appropriate conditioning and structured exercise training, even intensive competitive sports activities are possible.

In the future, innovative developments are conceivable in immunosuppressive medication, concomitant with impacts on the described transplant-related alterations, the clinical condition, and survival times. Likewise, the increased use of rate-responsive pacemakers is conceivable in order to minimise the consequences of chronotropic incompetence [28].

However, despite all conceivable improvements to HTX therapy, regular endurance and resistance training will continue to be the basis for adequate exercise capacity and can also contribute to mental stabilisation. Therefore, specific exercise programs should be offered to HTX recipients routinely and on a long-term basis beyond inpatient cardiac rehabilitation periods.

\section{Conflict of Interest}

None of the authors has a financial relationship with a commercial entity that has an interest in the subject of the presented manuscript or other conflicts of interest to disclose. The authors confirm that this manuscript adheres to the ethical standards in sports and exercise science research [94].

\section{References}

[1] Yancy CW, Jessup M, Bozkurt B et al. 2013 ACCF/AHA guideline for the management of heart failure: $A$ report of the American College of Cardiology Foundation/American Heart Association Task Force on Practice Guidelines. J Am Coll Cardiol 2013; 62: e147-e239

[2] Mosterd A, Hoes AW. Clinical epidemiology of heart failure. Heart 2007; 93: 1137-1146

[3] Roger VL, Weston SA, Redfield MM et al. Trends in heart failure incidence and survival in a community-based population. JAMA 2004; 292: $344-350$

[4] Stehlik J, Kobashigawa J, Hunt SA et al. Honoring 50 years of clinical heart transplantation in circulation: in-depth state-of-the-art review. Circulation 2018; 137: 71-87

[5] Emin A, Rogers CA, Banner NR. Quality of life of advanced chronic heart failure: Medical care, mechanical circulatory support and transplantation. Eur J Cardiothorac Surg 2016; 50: 269-273

[6] Lund LH, Edwards LB, Kucheryavaya AY et al. The Registry of the International Society for Heart and Lung Transplantation: Thirty-second Official Adult Heart Transplantation Report - 2015; Focus Theme: Early Graft Failure. J Heart Lung Transplant 2015; 34: 1244-1254

[7] Khush KK, Cherikh WS, Chambers DC et al. The International Thoracic Organ Transplant Registry of the International Society for Heart and Lung Transplantation: Thirty-sixth adult heart transplantation report - 2019; Focus theme: Donor and Recipient Size Match. J Heart Lung Transplant 2019; 38: 1056-1066 
[8] Lund LH, Edwards LB, Dipchand Al et al. The Registry of the International Society for Heart and Lung Transplantation: Thirty-third Adult Heart Transplantation Report- 2016; Focus Theme: Primary Diagnostic Indications for Transplant. J Heart Lung Transplant 2016; 35: 1158-1169

[9] Lund LH, Khush KK, Cherikh WS et al. The Registry of the International Society for Heart and Lung Transplantation: Thirty-fourth Adult Heart Transplantation Report - 2017; Focus Theme: Allograft Ischemic Time. J Heart Lung Transplant 2017; 36: 1037-1046

[10] Brown CR, Khurshan F, Chen Z et al. Optimal timing for heart transplantation in patients bridged with left ventricular assist devices: Is timing of the essence? J Thorac Cardiovasc Surg 2019; 157: 2315. e4-2324.e4

[11] Shiner CT, Woodbridge G, Skalicky DA et al. Multidisciplinary inpatient rehabilitation following heart and/or lung transplantation - examining cohort characteristics and clinical outcomes. PM R 2019; 11: 849-857

[12] Bjarnason-Wehrens B, Schmidt T, Reiss N. Exercise in specific diseases: heart transplantation and left ventricular assist device. In: Pressler A, Niebauer J, Eds. Textbook of Sports and Exercise Cardiology: Springer International Publishing; 2020: 977-1009

[13] Kavanagh T, Mertens D], Shephard RJ et al. Long-term cardiorespiratory results of exercise training following cardiac transplantation. Am J Cardiol 2003; 91: 190-194

[14] Zoll ], N'Guessan B, Ribera F et al. Preserved response of mitochondrial function to short-term endurance training in skeletal muscle of heart transplant recipients. J Am Coll Cardiol 2003; 42: 126-132

[15] Braith RW, Magyari PM, Pierce GL et al. Effect of resistance exercise on skeletal muscle myopathy in heart transplant recipients. Am J Cardiol 2005; 95: 1192-1198

[16] Bussières LM, Pflugfelder PW, Taylor AW et al. Changes in skeletal muscle morphology and biochemistry after cardiac transplantation. Am J Cardiol 1997; 79: 630-634

[17] Stratton JR, Kemp G], Daly RC et al. Effects of cardiac transplantation on bioenergetic abnormalities of skeletal muscle in congestive heart failure. Circulation 1994; 89: 1624-1631

[18] Lampert E, Mettauer B, Hoppeler $\mathrm{H}$ et al. Structure of skeletal muscle in heart transplant recipients. J Am Coll Cardiol 1996; 28: 980-984

[19] Braith RW, Edwards DG. Exercise following heart transplantation. Sports Med 2000; 30: 171-192

[20] Henderson NK, Sambrook PN, Kelly PJ et al. Bone mineral loss and recovery after cardiac transplantation. Lancet 1995; 346: 905

[21] Kobashigawa J, Olymbios M. Physiology of the transplanted heart. In: Kobashigawa J, Ed. Clinical Guide to Heart Transplantation: Springer International Publishing; 2017: 81-93

[22] Awad M, Czer LSC, Hou M et al. Early Denervation and later reinnervation of the heart following cardiac transplantation: A review. J Am Heart Assoc 2016; 5: e004070

[23] Kim IC, Youn JC, Kobashigawa JA. The Past, Present and Future of Heart Transplantation. Korean Circ J 2018; 48: 565-590

[24] Tallaj JA, Kirklin JK, Brown RN et al. Post-heart transplant diastolic dysfunction is a risk factor for mortality. J Am Coll Cardiol 2007; 50: 1064-1069

[25] Paulus WJ, Bronzwaer JG, Felice $\mathrm{H}$ et al. Deficient acceleration of left ventricular relaxation during exercise after heart transplantation. Circulation 1992; 86: 1175-1185

[26] Kao AC, van Trigt P, Shaeffer-McCall GS et al. Central and peripheral limitations to upright exercise in untrained cardiac transplant recipients. Circulation 1994; 89: 2605-2615

[27] Pflugfelder PW, Purves PD, McKenzie FN et al. Cardiac dynamics during supine exercise in cyclosporine-treated orthotopic heart transplant recipients: Assessment by radionuclide angiography. J Am Coll Cardiol 1987; 10: 336-341
[28] Braith RW, Clapp L, Brown T et al. Rate-responsive pacing improves exercise tolerance in heart transplant recipients: A pilot study. J Cardiopulm Rehabil 2000; 20: 377-382

[29] Braith RW, Wood CE, Limacher MC et al. Abnormal neuroendocrine responses during exercise in heart transplant recipients. Circulation 1992; 86: 1453-1463

[30] Costanzo MR, Dipchand A, Starling R et al. The International Society of Heart and Lung Transplantation Guidelines for the care of heart transplant recipients. J Heart Lung Transplant 2010; 29: 914-956

[31] Squires RW. Exercise therapy for cardiac transplant recipients. Prog Cardiovasc Dis 2011; 53: 429-436

[32] Vanhees L, Rauch B, Piepoli M et al. Importance of characteristics and modalities of physical activity and exercise in the management of cardiovascular health in individuals with cardiovascular disease (Part III). Eur J Prev Cardiol 2012; 19: 1333-1356

[33] Rosenbaum AN, Kremers WK, Schirger JA et al. Association between early cardiac rehabilitation and long-term survival in cardiac transplant recipients. Mayo Clin Proc 2016; 91: 149-156

[34] Anderson L, Nguyen TT, Dall CH et al. Exercise-based cardiac rehabilitation in heart transplant recipients. Cochrane Database Syst Rev 2017; 4: CD012264

[35] Nytrøen K, Gullestad L. Exercise after heart transplantation: an overview. World J Transplant 2013; 3: 78-90

[36] Hsieh P-L, Wu Y-T, Chao W-J. Effects of exercise training in heart transplant recipients: a meta-analysis. Cardiology 2011; 120: 27-35

[37] Didsbury M, McGee RG, Tong A et al. Exercise training in solid organ transplant recipients: a systematic review and meta-analysis. Transplantation 2013; 95: 679-687

[38] Tegtbur U, Busse MW, Jung K et al. Time course of physical reconditioning during exercise rehabilitation late after heart transplantation. J Heart Lung Transplant 2005; 24: 270-274

[39] Pascoalino LN, Ciolac EG, Tavares AC et al. Exercise training improves ambulatory blood pressure but not arterial stiffness in heart transplant recipients. J Heart Lung Transplant 2015; 34: 693-700

[40] Schmidt A, Pleiner J, Bayerle-Eder M et al. Regular physical exercise improves endothelial function in heart transplant recipients. Clin Transplant 2002; 16: 137-143

[41] Braith RW, Schofield RS, Hill JA et al. Exercise training attenuates progressive decline in brachial artery reactivity in heart transplant recipients. J Heart Lung Transplant 2008; 27: 52-59

[42] Pierce GL, Schofield RS, Casey DP et al. Effects of exercise training on forearm and calf vasodilation and proinflammatory markers in recent heart transplant recipients: A pilot study. Eur ] Cardiovas Prev Rehabil 2008; 15 : 10-18

[43] Karapolat H, Engin C, Eroglu M et al. Efficacy of the cardiac rehabilitation program in patients with end-stage heart failure, heart transplant patients, and left ventricular assist device recipients. Transplant Proc 2013; 45: 3381-3385

[44] Tegtbur U, Busse MW, Jung $\mathrm{K}$ et al. Phase III rehabilitation after heart transplantation. Z Kardiol 2003; 92: 908-915

[45] Wu Y-T, Chien C-L, Chou N-K et al. Efficacy of a home-based exercise program for orthotopic heart transplant recipients. Cardiology 2008; 111: 87-93

[46] Kugler C, Malehsa D, Tegtbur U et al. Health-related quality of life and exercise tolerance in recipients of heart transplants and left ventricular assist devices: A prospective, comparative study. J Heart Lung Transplant 2011; 30: 204-210

[47] Nytrøen K, Rolid K, Andreassen AK et al. Effect of high-intensity interval training in de novo heart transplant recipients in Scandinavia. Circulation 2019; 139: 2198-2211 
[48] Nytrøen K, Rustad LA, Aukrust P et al. High-intensity interval training improves peak oxygen uptake and muscular exercise capacity in heart transplant recipients. Am J Transplant 2012; 12: 3134-3142

[49] Rustad LA, Nytrøen K, Amundsen BH et al. One year of high-intensity interval training improves exercise capacity, but not left ventricular function in stable heart transplant recipients: a randomised controlled trial. Eur J Prev Cardiol 2014; 21: 181-191

[50] Monk-Hansen T, Dall CH, Christensen SB et al. Interval training does not modulate diastolic function in heart transplant recipients. Scand Cardiovasc J 2014; 48: 91-98

[51] Nytrøen K, Rustad LA, Erikstad I et al. Effect of high-intensity interval training on progression of cardiac allograft vasculopathy. J Heart Lung Transplant 2013; 32: 1073-1080

[52] Hermann TS, Dall CH, Christensen SB et al. Effect of high intensity exercise on peak oxygen uptake and endothelial function in long-term heart transplant recipients. Am J Transplant 2011; 11: 536-541

[53] Christensen SB, Dall CH, Prescott E et al. A high-intensity exercise program improves exercise capacity, self-perceived health, anxiety and depression in heart transplant recipients: A randomized, controlled trial. J Heart Lung Transplant 2012; 31: 106-107

[54] Dall CH, Snoer M, Christensen S et al. Effect of high-intensity training versus moderate training on peak oxygen uptake and chronotropic response in heart transplant recipients: a randomized crossover trial. Am J Transplant 2014; 14: 2391-2399

[55] Dall CH, Gustafsson F, Christensen SB et al. Effect of moderate- versus high-intensity exercise on vascular function, biomarkers and quality of life in heart transplant recipients: A randomized, crossover trial. J Heart Lung Transplant 2015; 34: 1033-1041

[56] Conraads VM, Pattyn N, Maeyer C de et al. Aerobic interval training and continuous training equally improve aerobic exercise capacity in patients with coronary artery disease: The SAINTEX-CAD study. Int ] Cardiol 2015; 179: 203-210

[57] Ellingsen $\varnothing$, Halle $M$, Conraads $\vee$ et al. High-intensity interval training in patients with heart failure with reduced ejection fraction. Circulation 2017; 135: 839-849

[58] Taylor JL, Holland DJ, Spathis JG et al. Guidelines for the delivery and monitoring of high intensity interval training in clinical populations. Prog Cardiovasc Dis 2019; 62: 140-146

[59] Braith RW, Mills RM, Welsch MA et al. Resistance exercise training restores bone mineral density in heart transplant recipients. J Am Coll Cardiol 1996; 28: 1471-1477

[60] Braith RW, Welsch MA, Mills RM et al. Resistance exercise prevents glucocorticoid-induced myopathy in heart transplant recipients. Med Sci Sports Exerc 1998; 30: 483-489

[61] Braith RW, Magyari PM, Fulton MN et al. Resistance exercise training and alendronate reverse glucocorticoid-induced osteoporosis in heart transplant recipients. J Heart Lung Transplant 2003; 22: 1082-1090

[62] Dew MA, Kormos RL, DiMartini AF et al. Prevalence and risk of depression and anxiety-related disorders during the first three years after heart transplantation. Psychosomatics 2001; 42: 300-313

[63] DeCampli WM. Of mice and men ... does exercise decrease progression of transplant coronary vasculopathy? J Thorac Cardiovasc Surg 2015; 149: 337-339

[64] Crespo-Leiro MG, Metra M, Lund LH et al. Advanced heart failure: a position statement of the Heart Failure Association of the European Society of Cardiology. Eur Heart J 2018; 20: 1505-1535

[65] Malhotra R, Bakken K, D'Elia E et al. Cardiopulmonary exercise testing in heart failure. JACC Heart Fail 2016; 4: 607-616

[66] Mathur S, Janaudis-Ferreira T, Wickerson L et al. Meeting report: consensus recommendations for a research agenda in exercise in solid organ transplantation. Am J Transplant 2014; 14: 2235-2245
[67] Tsai H-Y, Tsai W-J, Kuo L-Y et al. Oxygen consumption at anaerobic threshold predicts cardiac events after heart transplantation. Transplant Proc 2018; 50: 2742-2746

[68] Yardley M, Havik OE, Grov I et al. Peak oxygen uptake and self-reported physical health are strong predictors of long-term survival after heart transplantation. Clin Transplant 2016; 30: 161-169

[69] Raichlin E, Selim A, Zolty R et al. Cardiopulmonary stress test one year after HTx predicts the development of CAV. J Heart Lung Transplant 2017; 36: S296

[70] Doutreleau S, Di Marco P, Talha S et al. Can the six-minute walk test predict peak oxygen uptake in men with heart transplant? Arch Phys Med Rehabil 2009; 90: 51-57

[71] American Thoracic Society. ATS statement: guidelines for the six-minute walk test. Am J Respir Crit Care Med 2002; 166: 111-117

[72] Podsiadlo D, Richardson S. The timed "Up \& Go": A test of basic functional mobility for frail elderly persons. J Am Geriatr Soc 1991; 39 : $142-148$

[73] Guazzi M, Arena R, Halle M et al. 2016 focused update: Clinical recommendations for cardiopulmonary exercise testing data assessment in specific patient populations. Eur Heart J 2018; 39: 1144-1161

[74] Reiss N, Schmidt T, Mommertz S et al. Inert gas rebreathing - helpful tool in the management of left ventricular assist device patients. Perfusion 2018; 33: 335-338

[75] Agostoni P, Cattadori G, Apostolo A et al. Noninvasive measurement of cardiac output during exercise by inert gas rebreathing technique: a new tool for heart failure evaluation. ] Am Coll Cardiol 2005; 46: 1779-1781

[76] Innes E. Handgrip strength testing: A review of the literature. Aust Occup Ther ] 1999; 46: 120-140

[77] Reynolds JM, Gordon TJ, Robergs RA. Prediction of one repetition maximum strength from multiple repetition maximum testing and anthropometry. J Strength Cond Res 2006; 20: 584-592

[78] Guazzi M, Bandera F, Ozemek C et al. Cardiopulmonary exercise testing: What is its value? J Am Coll Cardiol 2017; 70: 1618-1636

[79] Pescatello LS.ed. ACSM's Guidelines for Exercise Testing and Prescription. $9^{\text {th }}$ ed. Baltimore, MD/Philadelphia, PA: Wolters Kluwer; Lippincott Williams \& Wilkins; 2014

[80] Berg K, Bjerre K, Clemmensen T et al. Silent ischemia and arrhythmia after heart transplantation: relation to cardiac allograft vasculopathy. J Heart Lung Transplant 2019; 38: S282

[81] Ehrman JK, Keteyian SJ, Levine AB et al. Exercise stress tests after cardiac transplantation. Am J Cardiol 1993; 71: 1372-1373

[82] Skorić B, Čikeš M, Ljubas Maček J et al. Cardiac allograft vasculopathy: diagnosis, therapy, and prognosis. Croat Med J 2014; 55: 562-576

[83] Gustafsson F, Hunt SA, Yeon SB. Heart transplantation: clinical manifestations, diagnosis, and prognosis of cardiac allograft vasculopathy. UpToDate. Retrieved May 15, 2020, from https://www. uptodate.com/contents/heart-transplantation-clinical-manifestationsdiagnosis-and-prognosis-of-cardiac-allograft-vasculopathy

[84] Sieg A, Weeks P, Krustchinsky L et al. Statin therapy in cardiac allograft vasculopathy progression in heart transplant patients: Does potency matter? Transplant Rev (Orlando) 2016; 30: 178-186

[85] Vilchez RA, Fung J, Kusne S. Cryptococcosis in organ transplant recipients: an overview. Am J Transplant 2002; 2: 575-580

[86] Cordes C. 4.10. Patienten nach Herztransplantation (HTX). In: AWMF - Arbeitsgemeinschaft der Wissenschaftlichen Medizinischen Fachgesellschaften, Ed. S3-Leitlinie zur kardiologischen Rehabilitation (LL-KardReha) im deutschsprachigen Raum Europas: Deutschland, Österreich, Schweiz (D-A-CH). Langversion - Teil 2020; 1: 91-94

[87] Kelly RL, Walsh JR, Paratz JD et al. Quadriceps muscle strength and body mass index are associated with estimates of physical activity postheart transplantation. Transplantation 2019; 103: 1253-1259 
[88] Chen S-Y, Lu P-C, Lan C et al. Six-minute walk test among heart transplant recipients. Transplant Proc 2014; 46: 929-933

[89] Anyanwu A, Treasure T. Prognosis after heart transplantation: Transplants alone cannot be the solution for end stage heart failure. BM] 2003; 326: 509-510

[90] Givertz MM, Hartley LH, Colucci WS. Long-term sequential changes in exercise capacity and chronotropic responsiveness after cardiac transplantation. Circulation 1997; 96: 232-237

[91] Schmidt T, Bjarnason-Wehrens B, Bartsch P et al. Exercise capacity and functional performance in heart failure patients supported by a left ventricular assist device at discharge from inpatient rehabilitation. Artif Organs 2018; 42: 22-30
[92] Schmidt T, Bjarnason-Wehrens B, Mommertz $S$ et al. Development of exercise-related values in heart failure patients supported with a left ventricular assist device. Int J Artif Organs 2019; 42: 201-206

[93] Haykowsky M], Halle M, Baggish A. Upper limits of aerobic power and performance in heart transplant recipients: Legacy effect of prior endurance training. Circulation 2018; 137: 650-652

[94] Harriss D], MacSween A, Atkinson G. Ethical standards in sport and exercise science research: 2020 update. Int J Sports Med 2019; 40: : 813-817 